\title{
Reactive powder concrete for façade elements - A sustainable approach
}

\author{
Urs Mueller ${ }^{a, *}$, Natalie Williams Portal ${ }^{a}$, Valle Chozas $^{b}$, Mathias Flansbjer $^{c}$, Inigo Larazza ${ }^{b}$, \\ Nelson da Silva a and Katarina Malaga ${ }^{a}$ \\ ${ }^{a} C B I$ Swedish Cement and Concrete Research Institute, Sweden \\ ${ }^{\mathrm{b}}$ ACCIONA Technological Centre, Spain \\ 'SP Technical Research Institute of Sweden, Sweden
}

\begin{abstract}
Reactive powder concrete (RPC) is a fairly novel material with extraordinary strength and durability properties. Due to these properties, it is increasingly being utilized for external façade cladding thus enabling a considerable reduction in the thickness of concrete elements. Commercial RPC formulations on the market are usually expensive and less sustainable due to high cement clinker contents. In this study, improved RPC formulations with higher amounts of supplementary cementitious materials (SCMs) were developed. The formulations were combined with different types of reinforcements ranging from steel fibres to fibre textile grids primarily to enhance the ductility and tensile strength of the composite material.

The results showed that even with clinker replacement levels of up to ca. $40 \%$ of the total binder amount, a satisfactory mechanical performance of the RPC mixes could still be achieved. A fairly steep strength gain rendered heat treatment unnecessary. The materials displayed good flow properties and a reasonably short initial setting time. The incorporation of carbon textile fibre grids proved to be highly effective in improving the post cracking behaviour of the RPC. The results validated a more sustainable approach for RPC applied to thin façade elements.
\end{abstract}

Keywords: Façade, reactive powder concrete, textile reinforcement, durability, strength

\section{Introduction}

Precast concrete façade elements or cladding for housing projects were already used since the end of the 1950s. In Sweden, pre-fabricated modular concrete buildings made the so-called Million Program possible, which was a housing project realized between the 1960s and the 1970s (Stenberg, 2013) and which reacted to the increasing demand for affordable housing during this time. The Million Program had equivalents in many other European countries and established the concrete pre-cast technique in the housing market. For a long time, standard steel reinforced concrete (RC) elements dominated the pre-cast market for cement based concrete building envelopes. From the 1960s to the 1980s, they dominated the architectural landscape in many urban areas all around the world. The disadvantage of RC is the thickness of elements, which is due to the necessary concrete cover for the reinforcement. For a situation pertaining to a building façade, the European concrete standard EN 206-1 (2013) would prescribe measures against carbonation with a minimum cover thickness of 30 to $35 \mathrm{~mm}$ over the reinforcement (exposure classes XC3/XC4). As a reminder, carbonation removes the concrete's inherent corrosion protection of its steel reinforcement

\footnotetext{
${ }^{*}$ Corresponding author: Urs Mueller, CBI Swedish Cement and Concrete Research Institute, Brinellgatan 4,50115 Borås, Sweden. Tel.: +46 10 5166849; E-mail: urs.mueller@cbi.se.
} 
(Andrade, 2009). This results in a total minimum thickness of a RC panel of around $80 \mathrm{~mm}$ including the thickness of the reinforcement (i.e. the cover has to protect both sides of the reinforcement) (Neville, 1983). In fact, many RC façade elements have this minimum thickness, which makes the elements particularly heavy and thick.

Over the last 15 years, new materials emerged on the market, enabling to drastically reduce the thickness and weight of pre-cast façade elements due to the removal of standard steel rebar and steel meshes against other reinforcement alternatives. Two of those are textile reinforced concrete (TRC) and ultra-high performance concrete (UHPC) or reactive powder concrete (RPC). Both, TRC and RPC/UHPC have been applied for façade elements in form of ventilated façade cladding (Engberts, 2006) or as sandwich elements (Hegger et al. 2008). More and more RPC/UHPC is used as a façade material since both show extraordinary high strength and durability (Ghoneim et al. 2010; Rebentrost et al. 2008; Müller et al., 2008).

The terms 'reactive powder concrete' and 'ultra-high performance concrete' are often used synonymously but RPC actually uses fine sand as aggregate (maximum $2 \mathrm{~mm}$ or smaller) and UHPC can have coarser aggregate sizes (maximum 8 to $16 \mathrm{~mm}$ ). Both are defined as materials with a compressive strength greater than $120 \mathrm{MPa}$ and a strongly reduced capillary porosity. Due to its high strength RPC is beyond the scope of most of the concrete standards: e.g. the maximum strength class of C100/115 in EN 206-1 stipulates a maximum characteristic compressive strength of concrete of $115 \mathrm{MPa}$ (cube strength). However, many countries require special permits for the structural applications of concretes with a strength class above C80/95. Applications of textile or fibre reinforced RPC/UHPC have therefore to be in tune with national regulations dealing with materials outside of the standards.

Heat curing of RPC/UHPC under ambient or water saturation pressure (steam curing) can considerably increase the mechanical strength in the range of 20 to 30\% (Schachinger et al., 2008; Müller et al., 2009), and heat curing at $90^{\circ} \mathrm{C}$ is an established process in pre-casting of UHPC/RPC elements (Rebentrost et al., 2008). An important point concerning RPC/UHPC is the high powder content, and to be more specific, high cement clinker content. The clinker content in RPC/UHPC is usually between 700 and $900 \mathrm{~kg} / \mathrm{m}^{3}$, which makes the material more expensive and seemingly less sustainable.

The presented topic in this paper was to explore the reduction of the high cement clinker content of RPC by a partial replacement with other materials. The goal was to investigate the replacement of clinker by supplementary cementitious materials (SCMs) without causing a loss of performance. Another important point was to be able to mix the RPC in a standard forced action mixer for concrete with a minimum use of superplasticizer. The work was performed within the EC funded project SESBE at two locations, in Sweden at CBI and in Spain at ACCIONA with locally available starting materials. RPC is used in this project as an outer and inner layer for innovative non-load bearing sandwich panels of a new type.

\section{Conceptual approach for textile reinforced reactive powder concrete}

The concept of RPC/UHPC is based on two main achievements:

i) an optimized particle size packing including very small particles and,

ii) a greatly reduced water content in the fresh mix (water/binder ratio, usually below 0.2 ).

The theory of particle packing has already been well investigated in many studies (de Larrard \& Sedran, 1994; Teichmann \& Schmid, 2004), and is based on using specific components which complement each other to form an evenly distributed particle size curve reaching from particles 
$\leq 0.1 \mathrm{~nm}$ to $\geq 1 \mathrm{~mm}$. Particle packing optimization will minimize void space and maximize the material density. Additionally, the optimization of the amount of the single binder and aggregate components will reduce the $\mathrm{w} / \mathrm{b}$ ratio, the amount of superplasticizer, and will enhance the workability of the fresh RPC mix. Within the SESBE project, carbon textile fibre reinforcement was chosen to reinforce the reactive powder concrete.

\section{1. $R P C$ mix design}

Starting materials were based on components available on the market. They consisted of those listed in Table 1. The mix design was optimized by a particle packing model according to Andreasen (1930), calculated with the software Emma by ELKEM ("Elkem Materials Mixture Analyser EMMA"). The mix design was adjusted to locally available materials in Sweden (by CBI) and Spain (by ACCIONA). In total three final mixes were designed: two by CBI in Sweden (RPC-CBI1, RPC-CBI2) and one by ACCIONA in Spain (RPC-ACC). The ACCIONA mix had ground granulated blast furnace slag as a main clinker replacement.

Table 1

Starting materials for the RPC mixes

\begin{tabular}{lcc}
\hline Components & Spain & Sweden \\
\hline CEM II/A-V 52.5 & & $\mathrm{X}$ \\
CEM I 52.5 & $\mathrm{X}$ & $\mathrm{X}$ \\
Fly ash class F & $\mathrm{X}$ & \\
Granulated blast furnace slag & $\mathrm{X}$ & $\mathrm{X}$ \\
Silica fume & $\mathrm{X}$ & $\mathrm{X}$ \\
Quartz filler & $\mathrm{X}$ & $\mathrm{X}$ \\
Sand 0/1 mm & & \\
Sand 0/2 mm & $\mathrm{X}$ & $\mathrm{X}$ \\
Superplasticizer & $\mathrm{X}$ & $\mathrm{X}$ \\
Tap water & $\mathrm{X}$ & \\
\hline
\end{tabular}

Figure 1 illustrates the volume proportions of the three RPC mixes and also shows the differences in composition compared to a standard concrete and a common UHPC mix. The complexity of the RPC mixes is significant, in that a RPC mix can easily consist of six to eight different components and the fine adjustment of those components is essential. If one component changes (e.g. type of cement) the entire mix may need to be re-optimized. As a consequence, RPC and UHPC are considered as not very robust concerning proportioning errors. This is the reason why RPC/UHPC is sometimes found as commercial ready mixed products in order to avoid errors connected to incorrect proportioning of the RPC components and why RPC/UHPC is mostly used for pre-cast applications.

The mixes were blended in both planetary mixers and in forced action concrete mixers. For the latter method the mixing process lasted a little longer (around 20 minutes) due to the lower mixing energy and low water/binder ratios, which were below 0.2 for all three mixes. After blending, the mixes behaved as self-compacting and bleeding was not observed. The slump flow of the mixes after one minute was $>80 \mathrm{~cm}$ (RPC-CBI1, RPC-CBI2) and $90 \mathrm{~cm}$ (RPC-ACC), respectively.

The RPC reinforcement consisted of a 2D carbon grid (Fig. 2). The carbon roving consisted of fibre bundles of $24 \mathrm{~K}$ (thousands of fibres), which were originally coated by a styrene-butadiene rubber (SBR). Some of the grids were additionally coated by a composite polymer coating in order to investigate the bond behaviour between reinforcement and the RPC matrix. The composite 


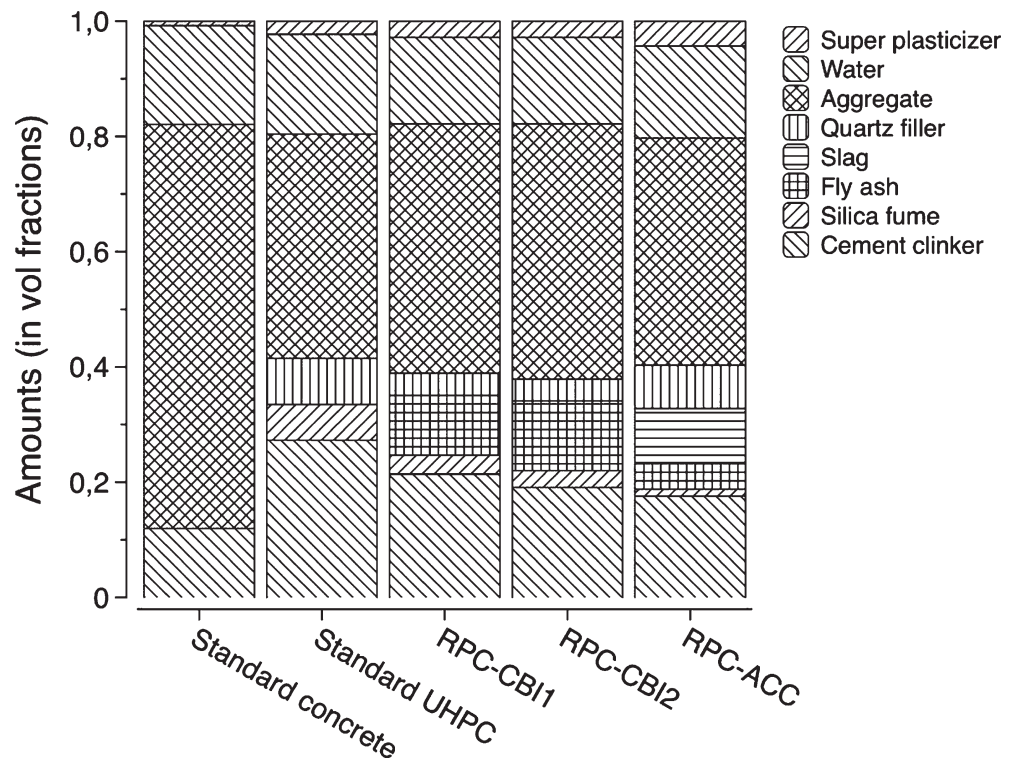

Fig. 1. RPC mix formulations compared to regular concrete and UHPC mixes (in volume fractions).

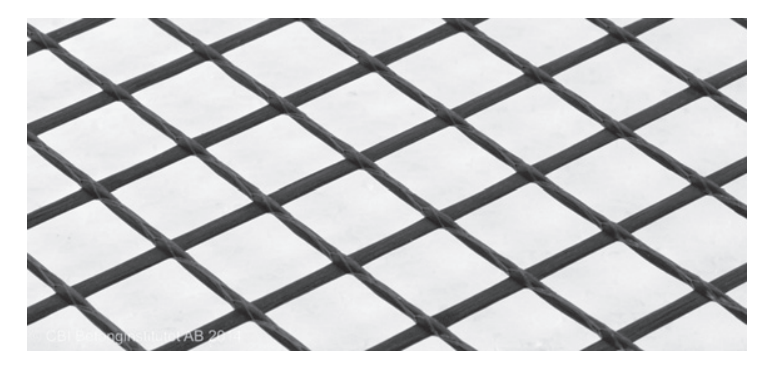

Fig. 2. The carbon textile fibre reinforcement in form of a $2 D$ grid.

polymer was developed within the SESBE project. In order to improve the fire resistance, RPC specimens with different amounts of polymer fibres were tested.

\subsection{Methods for testing properties}

The early age properties of the RPC mixes consisted of flow, setting and shrinkage measurements and are not reported here. General mechanical properties were measured for RPC without and with textile reinforcement. Strength testing without reinforcement was performed on mortar bars for screening purposes (compressive strength, $160 \mathrm{~mm} \times 40 \mathrm{~mm} \times 40 \mathrm{~mm}$ ) and on cylinders ( $\$ 54 \mathrm{~mm} \times 100 \mathrm{~mm}$ ) for compressive and tensile strength, modulus of elasticity as well as Poisson's ratio. These unreinforced sample specimens were generally stored under water prior until testing at $20^{\circ} \mathrm{C}$.

RPC is a fairly brittle material and tests with reinforcement should essentially demonstrate if the brittle behaviour can be improved by the incorporation of a textile grid. In practice, load on a panel is typically introduced in the form of bending forces due to lifting of the panels from the formwork (suction) and due to wind loads (pressure and suction). In case of initial cracks, the textile reinforcement will prevent a sudden collapse of the panel and under increased strain would 

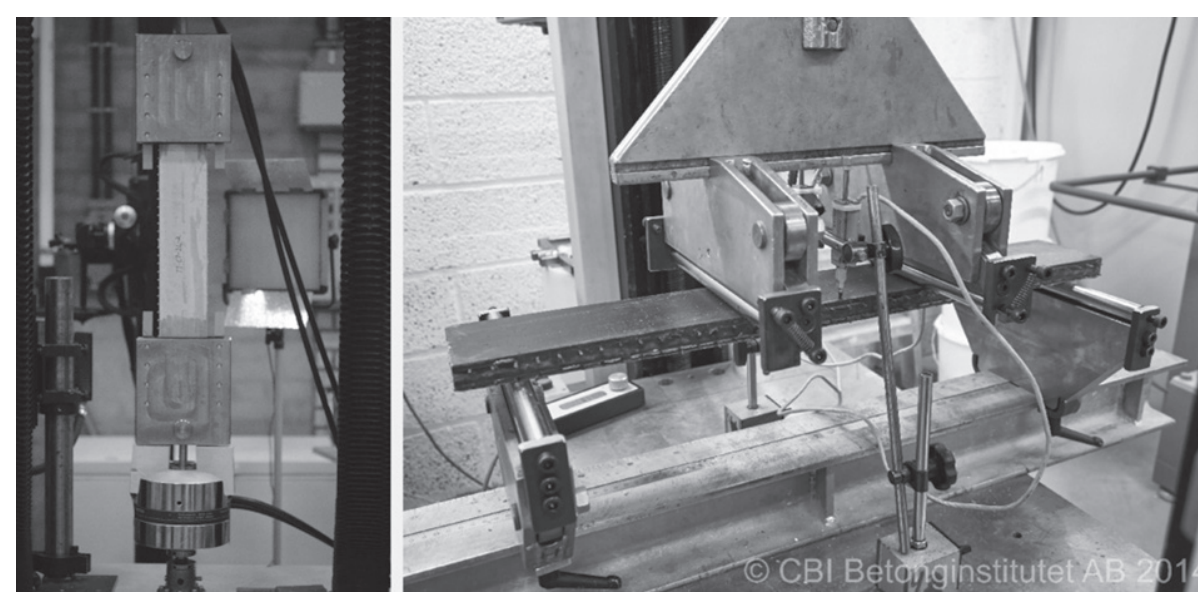

Fig. 3. Setup for tensile (left) and flexural strength testing (right).

be activated by controlling further cracking. The composite behaviour of RPC reinforced by textile reinforcement was investigated by tensile and four-point bending tests.

Reinforced RPC samples consisted of panels of the size $700 \mathrm{~mm} \times 100 \mathrm{~mm} \times 20 \mathrm{~mm}$, which included two layers of a 2D grid with a distance of $12 \mathrm{~mm}$. Two different electro mechanical universal testing machines were used as shown in Figure 3. The tensile test was performed according to the RILEM TC 232-TDT (2016) recommendation for textile reinforced concrete. Extensions in the tensile tests were measured by a Digital Image Correlation System (DIC), deflections in the flexural tests were measured by standard displacement transducers (LVDT) at mid-span. Initially, textile reinforced specimens were first stored under water, the same way as the samples without reinforcement. However, further storage was done in air at $20^{\circ} \mathrm{C}$ and $65 \% \mathrm{RH}$. The reason is explained below.

Durability was exemplarily tested on the RPC-CBI1 mix for freeze/thaw resistance, for chloride ingress and for fire resistance. Chloride ingress was tested according to the Rapid Chloride Migration Nordtest method (NT BUILD 492, 1999). The frost resistance test was performed according to the slab test with a $\mathrm{NaCl}$ solution (CEN/TS 12390-9, 2006). Both durability related test methods should give an indication about the long term performance of the RPC material.

The fire resistance of RPC specimen with different amounts of polymer fibre reinforcement was tested by a simple test setup in an oven with three burners (Fig. 4). The test was intended to investigate the tendency of RPC spalling. The burners heated the specimen within a defined profile up to a maximum temperature of $1000^{\circ} \mathrm{C}$ in about 5 minutes. The specimens were $400 \mathrm{~mm} \times 400 \mathrm{~mm} \times 50 \mathrm{~mm}$ in size and contained 8 steel reinforcement bars along the edges in order to restrain the samples and prevent early cracking (Fig. 4).

\section{Results and discussion}

\subsection{Results from mechanical tests without reinforcement}

The development of the compressive strength of the three different final RPC mixes is shown in Figure 5. All three strength curves followed a similar trend. After $28 \mathrm{~d}$ and $56 \mathrm{~d}$, respectively, the differences in strength were only marginal for all three mixes. However, mix RPC-CBI2 showed a lower strength within the first $24 \mathrm{~h}$ of hydration but still well above $20 \mathrm{MPa}$. It is important to note 

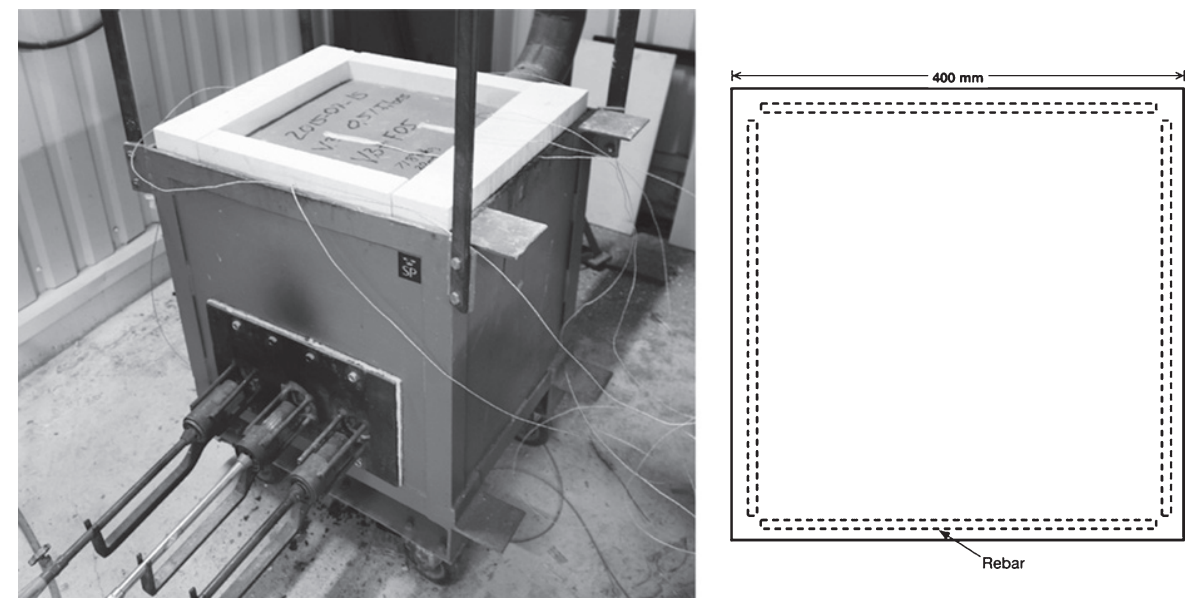

Fig. 4. Test setup for the fire test and the concrete test specimen with the steel rebars.

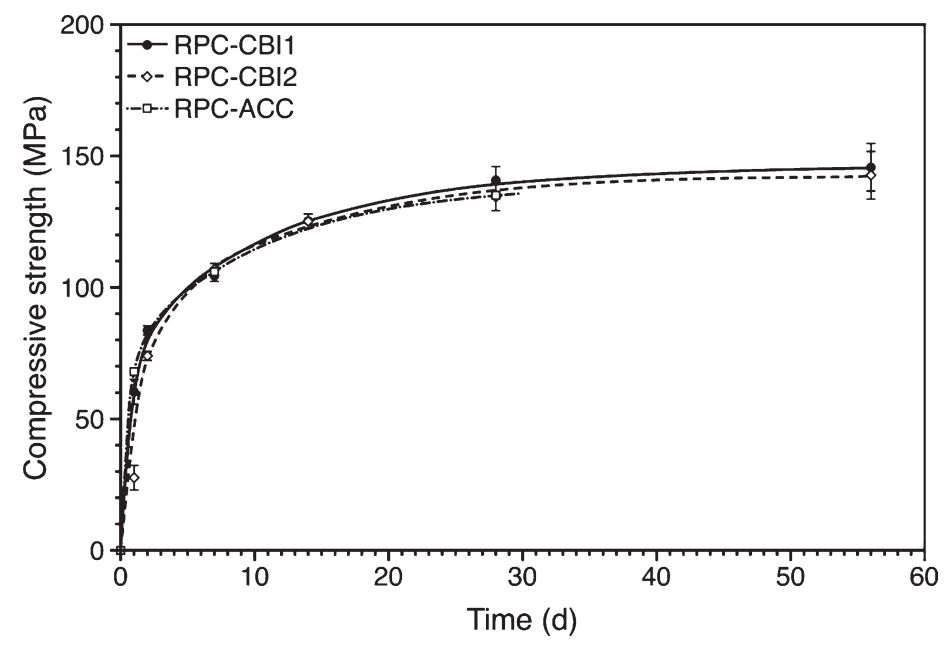

Fig. 5. Development of compressive strength for the three different mixes.

that after only a short time period, the compressive strength was significant. The initial setting time was determined for RPC-CBI1 at $5.5 \mathrm{~h}$ and RPC-CBI2 at $7 \mathrm{~h}$. The slower setting and lower initial strength of mix RPC-CBI2 was due to the higher content of fly ash in the mix.

Table 2 lists the results of specimens without reinforcement. The results show that the differences between the $\mathrm{CBI}$ and ACCIONA mixes are not significant. The high values of $50 \mathrm{GPa}$ for the E-modulus and the post peak behaviour indicate the extreme brittleness of the material, which manifested itself by a sudden and almost explosive failure if the maximum compressive forces were reached.

\subsection{Results from mechanical tests with reinforcement - tensile and flexural behaviour}

Initial tests were performed on mixes RPC-CBI1 and RPC-CBI2 with specimens which were stored submerged in water until the testing age of $28 \mathrm{~d}$. Results from tensile and flexural strength tests are given in Figures 6 and 7. Both mixes showed a similar failure mode. In both cases, minimal crack propagation took place, such that one crack (bending) and three cracks (tensile) 
Table 2

Summary of results mechanical strength ( $28 \mathrm{~d}$ ) of RPC mixes without reinforcement given as mean values and standard deviations in parenthesis

\begin{tabular}{lccccc}
\hline Mix & Comp. strength MPa & E-modulus GPa & Ultimate strain \%o & Poisson's ratio - & Tensile strength MPa \\
\hline RPC-CBI1 & $147.2(2.3)$ & $49.7(1.7)$ & $3.89(0.16)$ & $0.216(0.021)$ & $5.14(0.48)$ \\
RPC-CBI2 & $135.7(4.3)$ & $49.9(2.4)$ & $4.07(0.30)$ & $0.223(0.014)$ & $3.96(0.74)$ \\
RPC-ACC & 135.0 & 48.3 & - & 0.209 & - \\
\hline
\end{tabular}

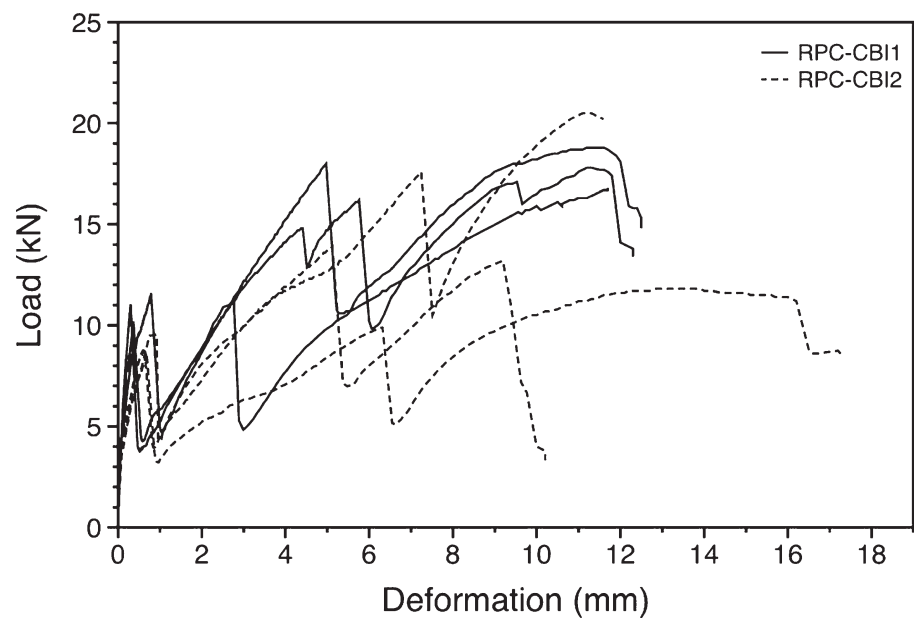

Fig. 6. Results from tensile tests with mix RPC-CBI1 and RPC-CBI2 with $2 \mathrm{D}$ carbon textile fibre reinforcement after 28 days of storage under water.

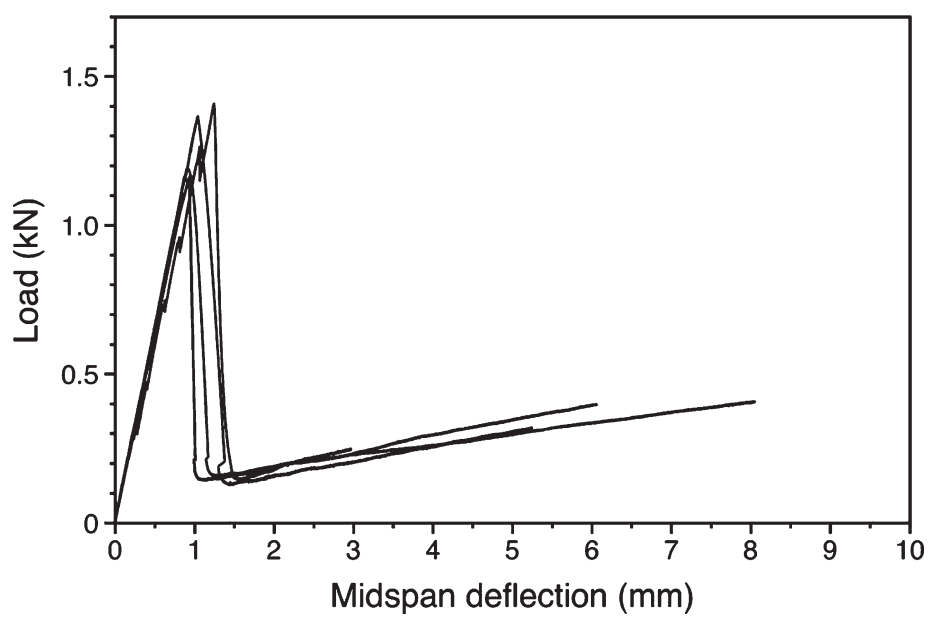

Fig. 7. Results from flexural tests with mix RPC-CBI1 with $2 \mathrm{D}$ carbon textile fibre reinforcement after 28 days of storage under water.

appeared (Figs. 6, 7). The initial part of the load versus mid-span deformation was relatively stiff for the un-cracked specimens. The crack formation was very brittle and a clear load drop in the load-deformation relation characterized the onset of a crack. Some smaller load drops could be attributed to minor cracking within the clamping length (Fig. 6). The observed behaviour is different to test results from textile reinforcement in standard or high strength concrete, wherein the textile 
reinforcement increases the ductility of the material to a certain level by distributing the load along the textile grid (Hegger \& Voss, 2008). As a consequence, the post peak performance is signified by a smaller drop in load and a much quicker gain of the original maximum load resulting in a multitude of small cracks within a panel.

The tensile and flexural results indicated a lack of sufficient bond between the textile reinforcement and the RPC. The lack of bond could be based on insufficient adhesion of the textile grid to the cementitious matrix and/or in the moisture content. A water saturated cementitious binder matrix probably adheres less well to a textile, which has been rendered mostly hydrophobic by the SBR coating, than a dry binder matrix. In order to prove the assumption additional tests were performed with test specimens, which were stored in a climate room at $20{ }^{\circ} \mathrm{C}$ and $65 \% \mathrm{RH}$. for 28 days after demoulding. During this time the samples lost moisture and equilibrated to the atmosphere in the climate room. Figure 8 illustrates the load versus mid-span curves from the flexural strength results of RPC-CBI1, indicating a much better bond by producing numerous cracks in the panels and a much better activation of the textile grid in the post peak range. When comparing with Figure 7, a large gain in mid-span deflection was observed. This illustrates that the water content in the samples has an effect on the activation of the textile grids under higher loads. However, the situation on a building façade would foster a rather dry façade material. RPC is very dense and water uptake is very slow. If some water uptake, due to e.g. driving rain, would occur, the high ratio of surface area to volume would dry the material quickly. These factors support the hypothesis of rather lower water contents in RPC façade materials, which improves the overall mechanical response of the textile reinforced RPC as demonstrated.

Another possibility of increasing the bond of the textile was tested by applying a coating material based on an inorganic-organic composite polymer. This composite polymer was brushed as a very thin film onto the carbon textile grid prior to sample preparation as a second coating. The results showed a clear improvement both in flexural strength as well as in the post peak performance for RPC-CBI1 and RPC ACC (Fig. 9). This indicated that the composite polymer coating indeed worked as a coupling between the carbon textile grid and the binder matrix. Besides water content and coating material other factors influence the response of the reinforced RPC under flexural and tensile load, such as textile grid size and the number of roving.

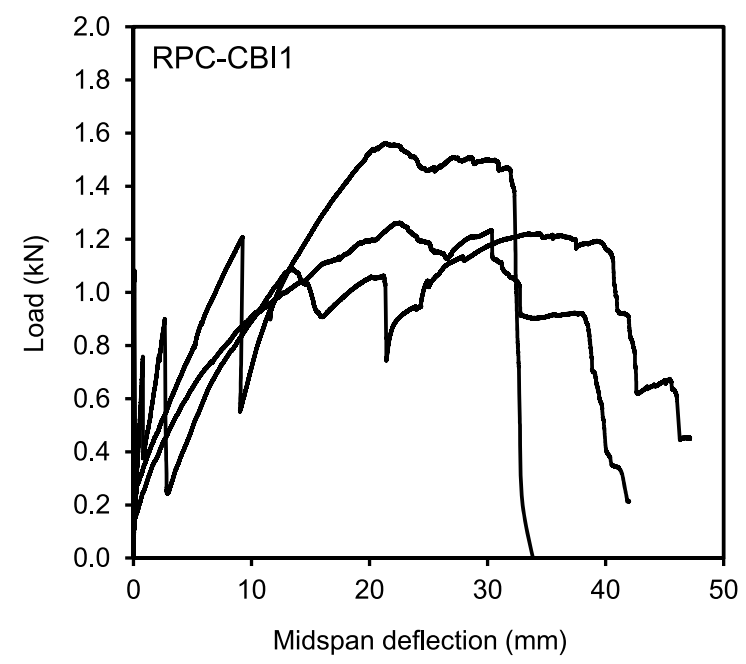

Fig. 8. Results from flexural tests with mix RPC-CBI1 with 2D carbon textile fibre reinforcement after 28 days of storage at $20^{\circ} \mathrm{C}$ and $65 \% \mathrm{RH}$. 

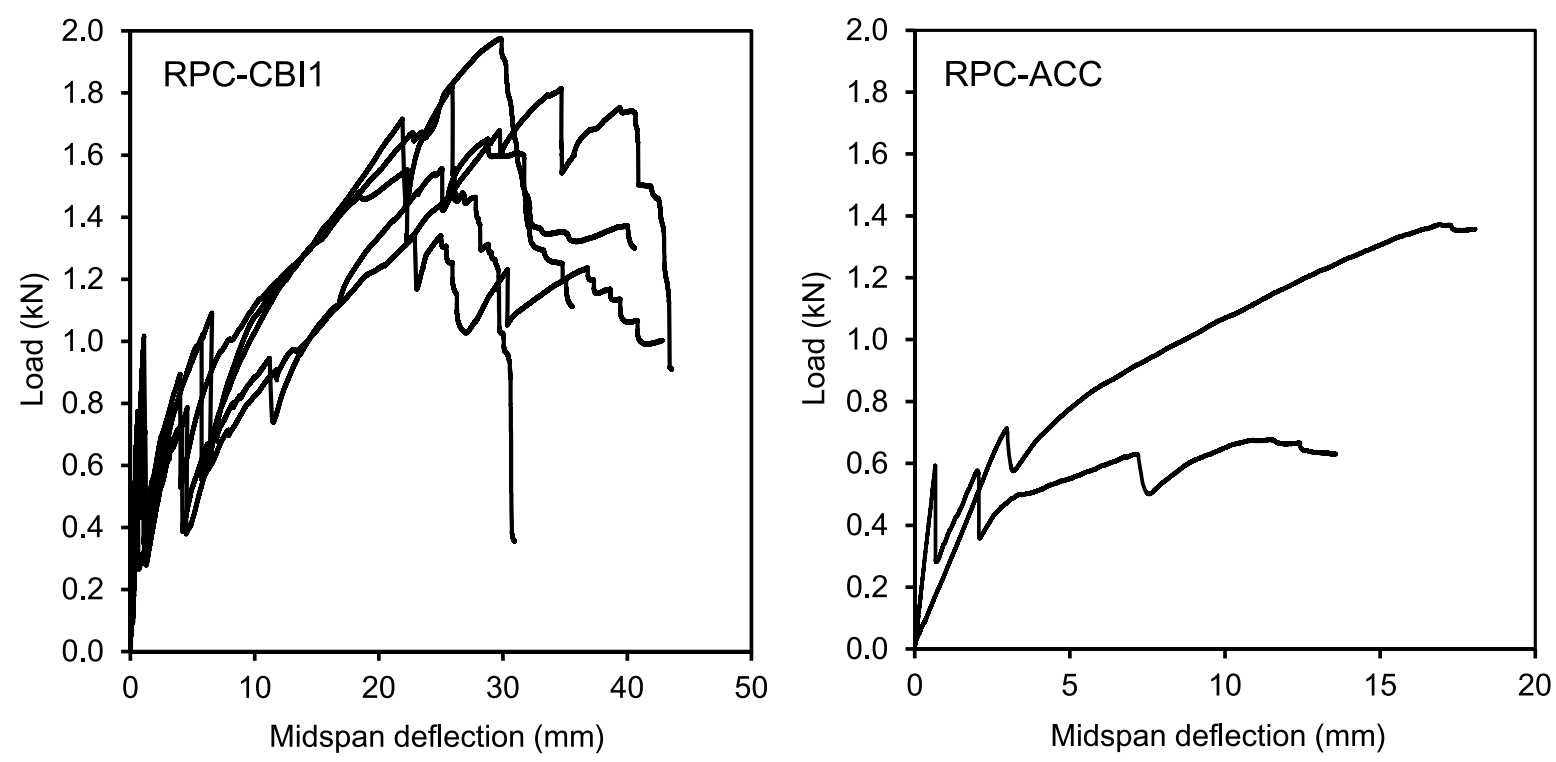

Fig. 9. Flexural strength test results after 28 days of storage at $20^{\circ} \mathrm{C}$ and $65 \% \mathrm{RH}$ with composite polymer coating on the 2D textile fibre reinforcement of the RPC-CBI1 series (left) and RPC-ACC series (right).

\subsection{Results from durability tests}

For façade applications in form of concrete sandwich panels or curtain walls, requirements focus towards carbonation and frost resistance. For these applications most national regulations require precautions according to the exposure classes XC4 and XF3 (EN 206-1, 2013). For the frost resistance of concrete, the requirements are nationally regulated. For Sweden XF3 requires an "acceptable" frost resistance, which is not more than $1 \mathrm{~kg} / \mathrm{m}^{2}$ in terms of scaling (SS 137244, 2005). If scaling is below $0.1 \mathrm{~kg} / \mathrm{m}^{2}$ after 56 cycles the concrete is considered to have "very good" frost resistance. The results as illustrated in Figure 10 show a scaling value of $0.05 \mathrm{~kg} / \mathrm{m}^{2}$ for the mix RPC-CBI1. According to the Swedish standard SS 137244 this represents a very good frost resistance, which is not only sufficient for XF3 but also for the exposure class XF4. Please note that the low scaling result of the RPC was achieved without any additional air entrainment.

The results for chloride migration showed very low values. The migration coefficient for RPC-CBI1 was $0.147 \times 10^{-12} \mathrm{~m}^{2} / \mathrm{s}$, which was one magnitude below the migration coefficients of standard concretes with different binders (Fig. 11). Similar low migration coefficients can be assumed for the other mixes RPC-CBI2 and RPC-ACC. Diffusion related transport processes such as carbonation or water absorption are of a similar low magnitude. The results indicate that RPC is an extremely durable product concerning resistance towards frost and migrating ions as well as water.

A critical issue of high or ultra-high performance cement based materials is fire resistance. Concrete, when heated up to high temperatures in a fairly short time, tends to build up steam within its microstructure and exert considerable forces, which eventually causes the concrete to spall (Heinz et al., 2004). This effect is the more drastic the denser the concrete is. However, spalling of concrete can be mitigated by adding polymer (mostly polypropylene, PP) fibres to the concrete. The polymer fibres melt when the concrete is heated up. The remaining voids prevent built-up of steam by venting it to the outside. To test the fire resistance, RPC specimens with four different fibre contents were prepared (mix RPC-CBI1): 0 vol. $\%, 0.14,0.51$ and 0.71 vol. $\%$ of PP fibres. Figure 12 illustrates the results for the specimen plates. Without and with 0.14 vol. \% 


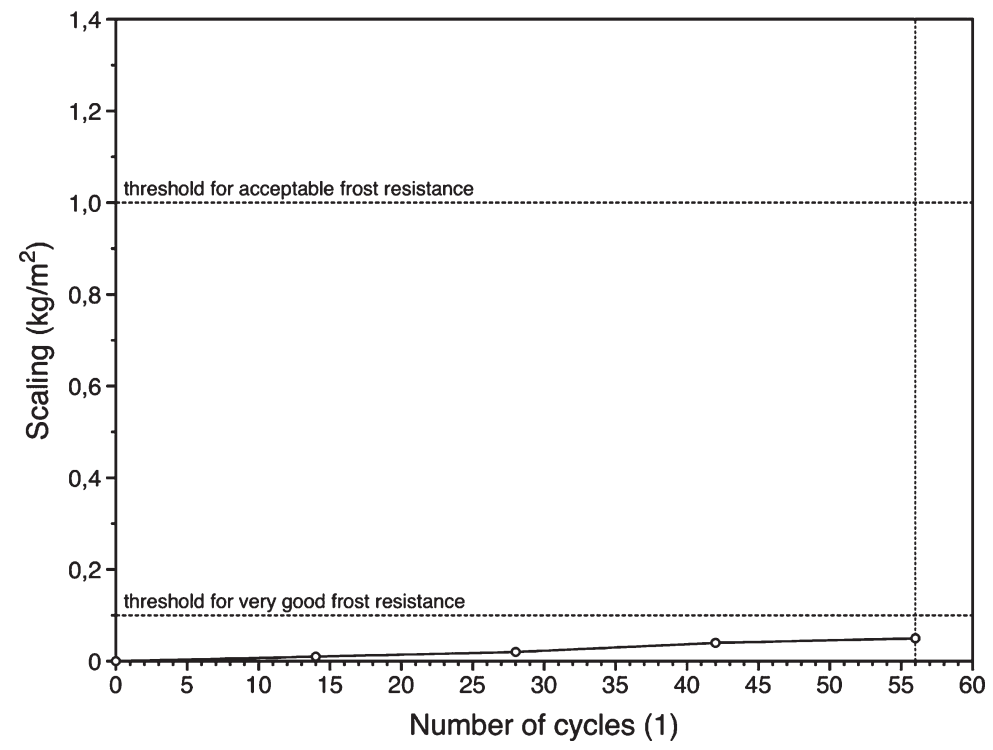

Fig. 10. Frost resistance in form of scaling of the mix RPC-CBI1 after 56 cycles. The threshold values give the frost resistance categories according to the Swedish standard SS 137244 (2005).

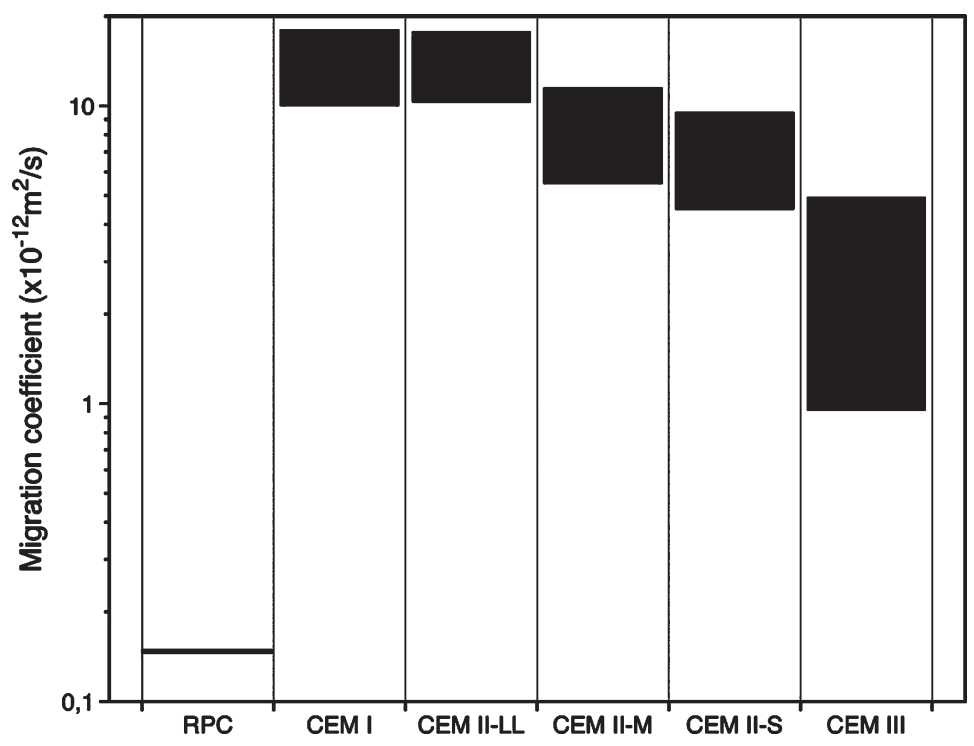

Fig. 11. Chloride migration coefficients of the RPC mix RPC-CBI1 compared to ranges of standard concretes with a w/c ratio of 0.5 (C. Müller, 2006). Note the y-axis is logarithmic.

fibres the RPC showed heavy spalling. Better results were achieved with amounts of 0.5 vol. \% of PP fibres. No spalling was detected at an amount of 0.71 vol. \% fibres. The addition of PP fibres reduces the flow of the concrete and makes the fresh RPC stickier and difficult to cast. However, if fire resistance of the RPC is important then a compromise has to be found between the sufficient amount of combustible fibres and the flow of the concrete by carefully adjusting the concrete's amount of water and superplasticizer. 


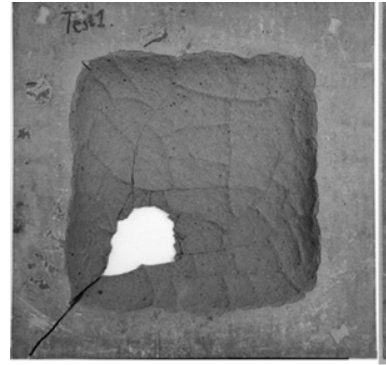

0 vol. \% fibres

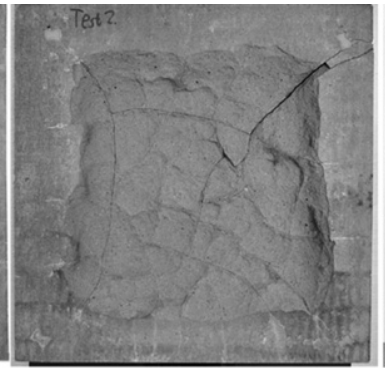

0.14 vol. $\%$

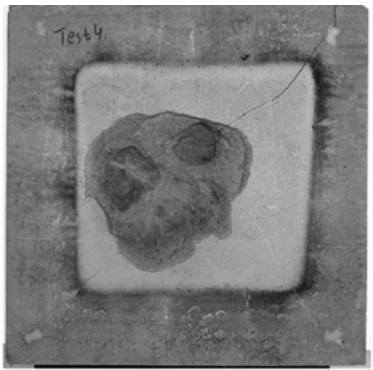

0.51 vol. $\%$

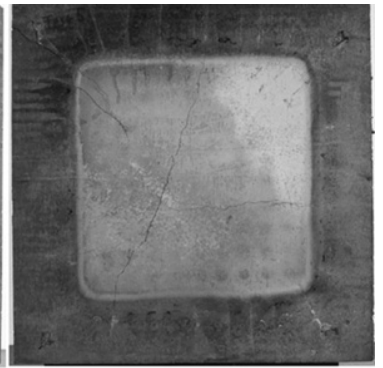

0.71 vol. $\%$

Fig. 12. Results of the fire test with mix RPC-CBI1 with different PP fibre contents up to a temperature of $1000{ }^{\circ} \mathrm{C}$.

\section{Aspects of sustainability}

Both approaches for a mix design, from $\mathrm{CBI}$ and ACCIONA, have shown that it is possible to create a reactive powder concrete with a high replacement level of clinker, which can harden sufficiently fast under ambient conditions. The mechanical properties lay within 135 to $150 \mathrm{MPa}$, which is more than enough for the envisaged panel applications. The replacement levels of both approaches were high, thus lowering the cement clinker content of RPC considerably (Fig. 13).

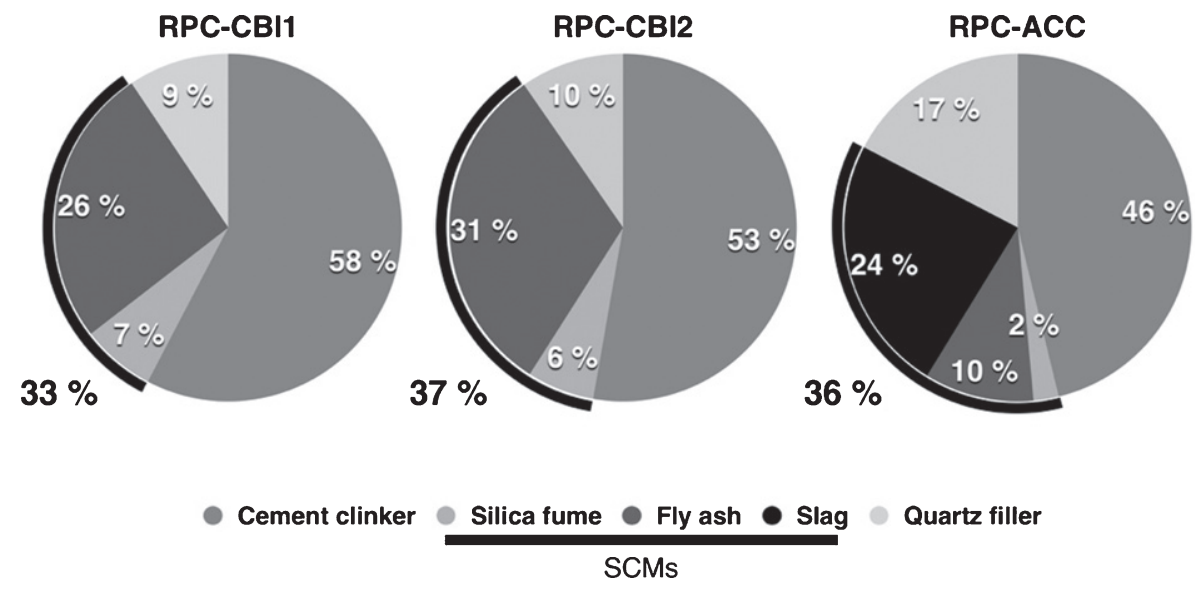

Fig. 13. Clinker replacement levels by supplementary cementitious materials (SCMs) for the RPC mix approaches of CBI and ACCIONA (on the total solid powder content, without aggregate).

From literature data of single components, the embodied energy of the textile reinforced RPC mixes was calculated in comparison to standard steel reinforced concrete. Figure 14 shows the results. As it can be seen for the RPC mixes the carbon fibre grid accounted for over $50 \%$ of the embodied energy. However, literature data on the embodied energy of carbon fibres vary greatly between $150 \mathrm{MJ} / \mathrm{kg}$ and up to $700 \mathrm{MJ} / \mathrm{kg}$, depending on the involved precursor materials, production processes and source data. Even though embodied energy based on the mass of the materials is not in favour of carbon textile reinforced RPC, the recalculation to square meter of façade is, due to the reduced thickness of panels cast in RPC (Fig. 15). The $30 \mathrm{~mm}$ thick panels of RPC exhibit only ca. $60 \%$ of the embodied energy of a standard reinforced concrete. From the cost point of view, the material price for carbon textile reinforced reactive powder concrete is still ca. 2.5 times higher compared to standard reinforced concrete (based on the prices used for the 


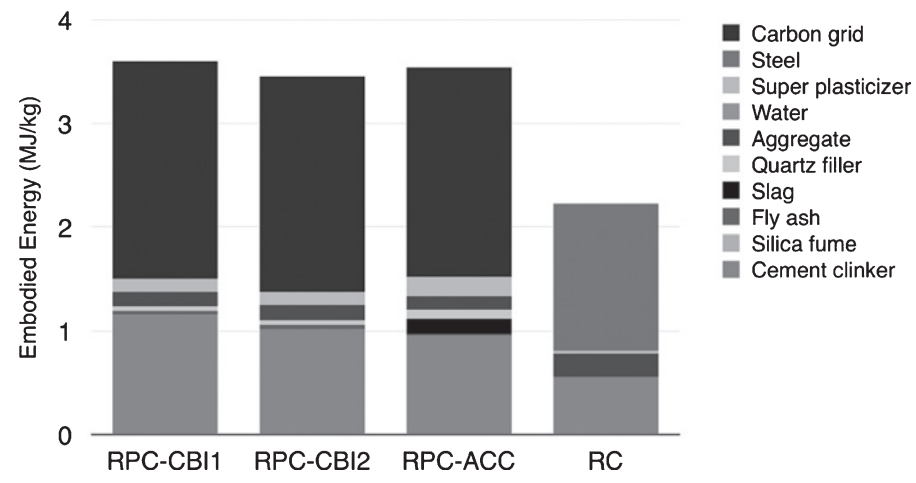

Fig. 14. Calculated embodied energies for the different RPC mixes, including reinforcement. As a comparison a standard steel reinforced concrete $(\mathrm{RC})$ was calculated. Note that the embodied energy is calculated for $1 \mathrm{~kg}$ of reinforced concrete.

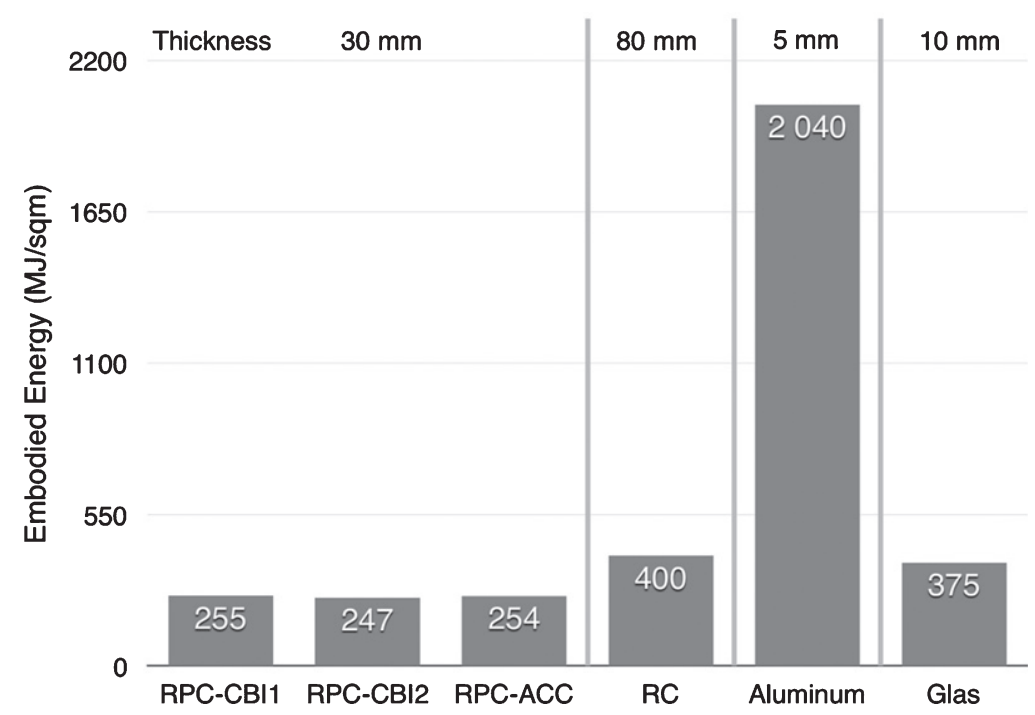

Fig. 15. Embodied energy for 1 square metre of façade material with different thicknesses. For comparison the embodied energy of standard steel reinforced concrete (RC), aluminium and glass is listed.

three RPC mixes). However, the higher material price can be compensated by reduced production, transport and mounting costs.

\section{Conclusions}

Designing a RPC mix is more challenging compared to a standard concrete mix since there are many more components, which need to be adjusted. Also, workability and setting is of prime importance for the production process of the panels and this is strongly related to the type and amount of RPC's constituents. If setting is excessively delayed because of too high amounts of clinker replacements, form-stripping times will be extended and the production process will no longer be profitable. Furthermore, it is desirable to reduce the amount of super plasticizer as much as possible in order to reduce the total costs of the concrete. Sustainability and costs can be further optimized by utilizing industrial waste products such as fly ash and slag. However, it has to be kept 
in mind that these so-called waste products have themselves become desired raw materials for cement and concrete production, which means that in practice their availability is limited as well.

It has been shown that the use of textile reinforced reactive powder concrete has benefits concerning material savings and sustainability. Due to the extraordinary strength and durability, façade applications in form of panels or cladding can be kept to a fraction of the thicknesses of a standard concrete panel. The brittle behaviour of the material can be counteracted by the incorporation of a textile grid based on carbon fibres. The textile grid increases the load capacity of the composite material considerably while allowing for controlled cracking as a part of the post peak performance.

However, the high strength and low density makes RPC more vulnerable to fire. If improved fire safety is required, the incorporation of a sufficient amount of polymer fibres may be advisable in order to prevent spalling of the concrete in case of massive fires.

\section{Acknowledgments}

The SESBE project is supported by the European Commission within the Framework Programme 7 under the Grant Agreement no. 608950. The authors would like to thank the European Commission for funding the project and making this work possible.

\section{References}

Andrade, C. (2009). Reinforcement corrosion: Research needs. Concrete Repair, Rehabilitation and Retrofitting II, ISBN 978-0, 81-88. Andreasen, A. H. M. (1930). Über die Beziehung zwischen Kornabstufung und Zwischenraum in Produkten aus losen Körnern (mit einigen Experimenten). Kolloid-Zeitschrift, 50(3), 217-228. doi:10.1007/BF01422986

CEN/TS 12390-9. Testing hardened concrete - Part 9: Freeze-thaw resistance - Scaling (2006).

de Larrard, F., \& Sedran, T. (1994). Optimization of ultra-high-performance concrete by the use of a packing model. Cement and Concrete Research, 24(6), 997-1009. Retrieved from http://www.sciencedirect.com/science/article/B6TWG-47XBYBD$\mathrm{J} 7 / 2 / 87 \mathrm{a} 423072 \mathrm{f} 64 \mathrm{e} 7 \mathrm{cb} 8 \mathrm{cda0} 098676 \mathrm{febc62}$

Elkem Materials Mixture Analyser - EMMA. (n.d.). Retrieved from https://www.elkem.com/download-centre/?query=emma\&tags= Refractories\&cat=EN206-1. Concrete - Specification, performance, production and conformity. (2013).

Engberts, E. (2006). Large-size façade Elements of textile reinforced concrete. In 1st International RILEM Conference on Textile Reinforced Concrete (pp. 309-318). RILEM Publications SARL.

Ghoneim, G., El-Hacha, R., Carson, G., \& Zakariasen, D. (2010). Precast Ultra High Performance Fibre Reinforced Concrete Replaces Stone And Granite On Building Façade. In Proceedings of the 3rd fib International Congress - 2010 (pp. 1-15).

Hegger, J., Horstmann, M., \& Scholzen, A. (2008). Sandwich Panels with Thin-Walled Textile-Reinforced Concrete Facings. In C.-M. Aldea (Ed.), Design and Applications of Textile Reinforced Concrete (pp. 109-123). American Concrete Institute. Retrieved from http://trid.trb.org/view.aspx?id=868282

Hegger, J., \& Voss, S. (2008). Investigations on the bearing behaviour and application potential of textile reinforced concrete. Engineering Structures, 30(7), 2050-2056. doi:10.1016/j.engstruct.2008.01.006

Heinz, D., Urbonas, L., \& Dehn, F. (2004). Fire resistance of ultra high performance concrete (UHPC) - Testing of laboratory samples and columns under load. In M. Schmidt, E. Fehling, \& C. Geisenhanslüke (Eds.), International Symposium on Ultra High Performance Concrete (pp. 703-715). Kassel: Kassel University Press.

Müller, C. (2006). Production and Application of Blended Cements.

Müller, U., Lehmann, C., Fontana, P., \& Meng, B. (2009). Effects of autoclaving on the nano structure and phase composition of Ultra High Performance Concrete. In B. Middendorf, A. Just, D. Klein, A. Glaubitt, \& J. Simon (Eds.), 12th Euroseminar on Microscopy Applied to Building Materials (pp. 351-359). Dortmund: Technical University of Dortmund.

Müller, U., Meng, B., Kühne, H.-C., Nemecek, J., Fontana, P., \& Fehling, E. (2008). Micro texture and mechanical properties of heat treated and autoclaved Ultra High Performance Concrete (UHPC). In E. Fehling, M. Schmidt, \& S. Stürwald (Eds.), 2nd International Symposium on Ultra High Performance Concrete (Heft 10., pp. 213-220). Kassel, Germany: Kassel University Press.

Neville, A. (1983). Corrosion of Reinforcement. Concrete, 17(6), 48-49.

NT BUILD 492. Concrete, mortars and cement-based repair materials: Chloride migration coefficient from non-steady-state migration experiments (1999).

Rebentrost, M., Wight, G., \& Fehling, E. (2008). Experience and Applications of Ultra-high Performance Concrete in Asia. In E. Fehling, M. Schmidt, \& S. Stürwald (Eds.), 2nd International Symposium on Ultra High Performance Concrete (Heft 10., pp. 19-30). Kassel, Germany: Kassel University Press. 
RILEM-Method. RILEM TC 232-TDT. Test methods and design of textile reinforced concrete: Uniaxial tensile test - Test method to determine the load bearing behaviour of tensile specimens made of textile reinforced concrete (2016). RILEM Recommendation.

Schachinger, I., Hilbig, H., Stengel, T., \& Fehling, E. (2008). Effect of Curing Temperature at an Early Age on the Long-Term Strength Development of UHPC. In E. Fehling, M. Schmidt, \& S. Stürwald (Eds.), 2nd International Symposium on Ultra High Performance Concrete (Heft 10., pp. 205-213). Kassel, Germany: Kassel University Press.

SS 137244. Concrete testing - Hardened concrete - Scaling at freezing (2005).

Stenberg, E. (2013). Structural Systems of the Million Program Era. KTH School of Architecture.

Teichmann, T., \& Schmid, M. (2004). Influence of the packing density of fine particles on structure, strength and durability of UHPC. In M. Schmidt, E. Fehling, \& C. Geisenhanslüke (Eds.), International Symposium on Ultra High Performance Concrete (pp. 313-323). Kassel: Kassel University Press. 